\title{
The Metabolic Role of Gut Microbiota in the Development of Nonalcoholic Fatty Liver Disease and Cardiovascular Disease
}

\author{
Marco Sanduzzi Zamparelli ${ }^{1}$, Debora Compare ${ }^{1}$, Pietro Coccoli ${ }^{1}$, Alba Rocco ${ }^{1}$, \\ Olga Maria Nardone ${ }^{1}$, Giuseppe Marrone ${ }^{2}$, Antonio Gasbarrini ${ }^{2}$, Antonio Grieco ${ }^{2}$, \\ Gerardo Nardone ${ }^{2, *}$ and Luca Miele ${ }^{2, *}$ \\ 1 Department of Clinical Medicine and Surgery, Gastroenterology Unit, Federico II University of Naples, \\ 80131 Napoli, Italy; marcosanduzzizamparelli@yahoo.it (M.S.Z.); comparedebora@libero.it (D.C.); \\ pietro.coccoli@unina.it (P.C.); a.rocco@unina.it (A.R.); olga.nardone@libero.it (O.M.N.) \\ 2 Internal Medicine and Gastroenterology Area, Fondazione Policlinico Universitario A. Gemelli, \\ Catholic University of Rome, 00168 Rome, Italy; giusmarrone@gmail.com (G.M.); \\ antonio.gasbarrini@unicatt.it (A.G.); antonio.grieco@unicatt.it (A.G.) \\ * Correspondence: luca.miele@policlinicogemelli.it (L.M.); nardone@unina.it (G.N.); \\ Tel.: +39-06-3015-5451 (L.M. \& G.N.)
}

Academic Editor: Johannes Haybaeck

Received: 7 June 2016; Accepted: 14 July 2016; Published: 29 July 2016

\begin{abstract}
The prevalence of metabolic disorders, such as type 2 diabetes (T2D), obesity, and non-alcoholic fatty liver disease (NAFLD), which are common risk factors for cardiovascular disease (CVD), has dramatically increased worldwide over the last decades. Although dietary habit is the main etiologic factor, there is an imperfect correlation between dietary habits and the development of metabolic disease. Recently, research has focused on the role of the microbiome in the development of these disorders. Indeed, gut microbiota is implicated in many metabolic functions and an altered gut microbiota is reported in metabolic disorders. Here we provide evidence linking gut microbiota and metabolic diseases, focusing on the pathogenetic mechanisms underlying this association.
\end{abstract}

Keywords: gut microbiota; cardiovascular disease; NAFLD

\section{Introduction}

According to the World Health Organization cardiovascular disease (CVD) remains the leading cause of death in Western countries, accounting for about 20 million deaths/year worldwide [1]. Nevertheless, the prevalence of metabolic diseases, such as type 2 diabetes (T2D), obesity, and non-alcoholic fatty liver disease (NAFLD), which are common risk factors for CVD, has dramatically increased over the last decades worldwide.

Both genetic susceptibility and environmental factors contribute to cardio-metabolic pathogenesis. Unfortunately, despite the introduction of new extensive investigation on genetic determinants, such as large-scale genome-wide association study (GWAS), only a few cases can be assigned to genetic factors [2,3]. Thus, the environmental component seems to be primarily involved in CVD burden.

The largest environmental exposure is food that we take into our intestine in kilogram quantities every day. However, there is an imperfect correlation between dietary habits and the development of metabolic disease. Diet, on the other hand, is known to deeply alter the microbiota composition in the gut. Therefore, recent evidence focused on the role of the gut microbiota in cardio-metabolic disorders and growing interest is aimed to modulate the gut microbiota as a therapeutic strategy. 


\section{Gut Microbiota}

The human gut harbors an enormously complex, dynamic, and vast microbial community that is composed mainly of bacteria, but also includes viruses, fungi, protozoa, and archaea [4]. The gut microbiota is estimated to consist of at least 1014 bacteria and archaea, including more than 1100 species and 150-fold more genes than our own host genomes [5].

The introduction of culture-independent methods to study the microbial community revealed the complexity of the gut microbiota. The human gut microbiota is dominated by bacteria belonging to four major phyla: Firmicutes, Bacteroidetes, Actinobacteria (representing $>95 \%$ of the total microbiota), and Proteobacteria [6]. Interestingly, Actinobacteria and Proteobacteria are more abundant in childhood, while Firmicutes and Bacteroidetes are prevalent in adulthood.

The fetal human gut was supposed to be sterile at birth; however, very recently, it has been reported that there is a passage of microbes between the mother and the fetus through the placenta. The most important colonization of the gastrointestinal tract starts suddenly after the birth and depends on delivery type, maternal flora, environment hygiene, and infant diet. During the first years of life, the gut microbiota composition is widely shifting and changeable, while it stabilizes when the infant reaches 1-3 years of age [7]. Microbial density increases from the proximal to the distal gut, and along the mucosal-lumen axis [8]. Similarly to bacterial density, microbial diversity also increases along the same axis.

The composition of the gut microbiota is dynamically influenced by several host factors, including diet, lifestyle, antibiotics, and genetic background. In a C57B/L6J mouse model, the use of antibiotics, in early life, alters the host metabolism and adiposity by a modification of the microbiome [9]. Another study described that the maternal administration of antibiotics during the last six months before the pregnancy or the early infancy is related to reduced bacterial diversity of the feces of the neonate, decreased levels of Lactobacilli and Bifidobacteria, and increased risk of childhood obesity [10].

Diet seems to play a critical role, being linked to quantitative and qualitative modifications of the microbiota composition. A study comparing the gut microbiota of Italian children with those living in a rural African village showed that Bacteroidetes levels (mainly Prevotella) were higher in the stool of African children who consumed high amounts of plant polysaccharides while Enterobacteriaceae levels were higher in the stool of Italian children [11].

Recently, exercise has also been demonstrated to modulate gut microbiota composition, showing qualitative and quantitative modifications after running [12] in voluntary athletes.

\section{Gut Microbiota and Energy Balance}

\subsection{Carbohydrate Metabolism}

\subsubsection{Animal Studies}

The gut microbes can benefit the host by extracting energies from otherwise non-digestible carbohydrates and plant polysaccharides via enzymes not encoded by humans [13]. Indeed, indigestible polysaccharides are fermented by colonic microbiota, leading to the generation of short-chain fatty acids (SCFAs) in the form of acetate $(60 \%)$, propionate $(25 \%)$, and butyrate $(15 \%)$. SCFAs are readily absorbed in the colon, where butyrate is an important energy source for colonic epithelial cells, while acetate and propionate reach the liver and peripheral organs, where they are used as substrates for gluconeogenesis [14].

SCFAs can also regulate gene expression by acting as signaling molecules, by binding to G-protein-coupled receptors (GPCRs), such as GPR41 (free fatty acid receptor, FFAR3) and GPR43 (FFAR2) [15]. A recent study demonstrated that GPR43-deficient mice, even if fed with a low-fat diet, are obese, while mice overexpressing GPR43 in adipose tissue are lean, even if under a high-fat diet (HFD) [16]. SCFAs-dependent activation of GPR43 can modulate insulin signaling in the adipose tissue, thus preventing fat accumulation. 
Furthermore, SCFAs directly modulate intestinal gluconeogenesis. Propionate affected intestinal gluconeogenesis via the gut-brain neuronal circuit, involving GPR41 and butyrate through cyclic adenosine monophosphate (cAMP)-dependent pathway, independently of GPR43 [17].

As far as butyrate is concerned, it is able to regulate the appetite via the central nervous system, by stimulating the liberation of peptide YY (PYY) and the satietogenic hormones glucagon-like peptide 1 (GLP-1) from enteroendocrine L-cells in the distal small intestine and the colon [18]. PYY is an intestinal hormone [19] known for its ability to decrease intestinal transit rate and increase the harvest of energy from the diet, while GLP-1 improves adipocyte insulin sensitivity and remarkably reduces fat storage in adipose tissue [20].

Gut microbes can also control the metabolic activity of the host by affecting the composition and the abundance of certain bile acid species [21]. The cholic and chenodeoxycholic acids are produced in the liver from cholesterol, and are needed for the absorption of cholesterol, dietary fats, and fat-soluble vitamins. In the ileum microbes deconjugate these bile acids, which escape intestinal uptake, and are converted into secondary bile acids. Bile acids can also act as signaling molecules by binding cellular receptors, such as the bile-acid-synthesis controlling nuclear receptor farnesoid X receptor (FXR), GPCR, and the G protein-coupled bile acid receptor TGR5 [22]. While primary bile acids can impair glucose metabolism by binding FXR [23], secondary bile acids (deoxycholic and chenodeoxycholic acid) improve glucose homeostasis by binding TGR5 [24] (Figure 1).

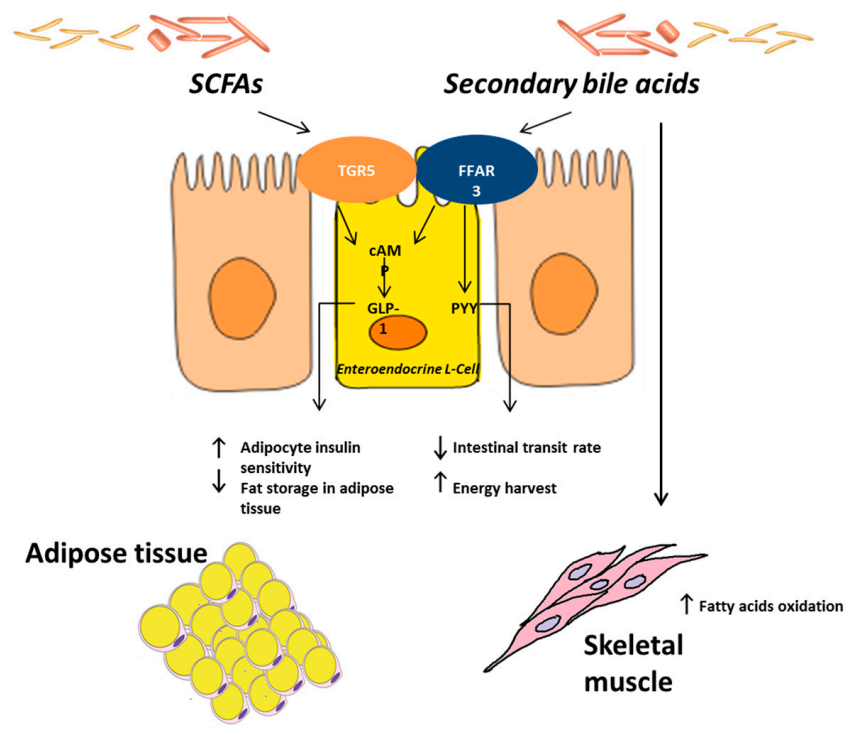

Figure 1. Gut microbiota and energy balance. The gut microbes can benefit the host by extracting energies from otherwise non-digestible carbohydrates and plant polysaccharides via enzymes not encoded by humans. Short-chain fatty acids (SCFAs) modulate intestinal gluconeogenesis via the gut-brain neuronal circuit, involving GPR41 (free fatty acid receptor, FFAR3) and through the cyclic adenosine monophosphate (cAMP)-dependent pathway. Butyrate is able to regulate the appetite in the central nervous system by stimulating the liberation of peptide YY (PYY) and the satietogenic hormone glucagon-like peptide 1 (GLP-1) from enteroendocrine L-cells. PYY decreases the intestinal transit rate and increases the harvest of energy from the diet, while GLP-1 improves adipocyte insulin sensitivity and remarkably reduces fat storage in adipose tissue. Gut microbes can also control the metabolic activity of the host by affecting the composition and the abundance of certain bile acid species. In the ileum microbes deconjugate cholic and chenodeoxycholic acids, which escape intestinal uptake, and are converted into secondary bile acids. Bile acids can also act as signaling molecules by binding cellular receptors such as the bile-acid-synthesis controlling nuclear receptor farnesoid $\mathrm{X}$ receptor (FXR), G-protein-coupled receptors (GPCR), and TGR5. While primary bile acids can impair glucose metabolism by binding FXR, secondary bile acids, by binding TGR5, improve glucose homeostasis and increase energy expenditure in skeletal muscle. 
Furthermore, animal studies demonstrated that Akkermansia muciniphila concentrations are inversely correlated with the body weight and glucose tolerance [25]. Hansen et al. recently demonstrated that vancomycin administration in non-obese diabetic rats increased A. muciniphila levels and ameliorated glucose homeostasis [26].

\subsubsection{Human Studies}

In humans, a metagenome-wide association study demonstrated significant modifications of specific gut microbes and metabolic pathways in T2D patients [27]. The study was performed using stool samples of 344 Chinese patients and showed a diminution of butyrate-producing bacteria, such as Roseburia intestinalis and Faecalibacterium prausnitzii, and an abundance of Akkermansia muciniphila. Recently, an interesting study conducted in Europe on postmenopausal patients with normal, impaired, or diabetic glucose regulation, showed somewhat contradictory results in comparison to the Chinese study. Different techniques, but also ethnic and dietetic factors, can account for the discrepancy [28].

A previous, smaller study demonstrated higher levels of Lactobacillus spp. in T2D patients in comparison to healthy controls [29] and both Chinese and European studies showed enhanced concentration of Lactobacillus gasseri, Streptococcus mutans and certain Clostridiales, and lower levels of Roseburia intestinalis and Faecalibacterium prausnittzii, in the diabetic cohort.

Moreover, certain antidiabetic medications can produce modification of the gut microbiota composition. A recent paper demonstrated that metformin administration resulted in increased levels of A. muciniphila, improvement of glucose tolerance, and reduced systemic inflammation [30,31]. In this light, the administration of prebiotics, such as oligofructose, increased A. muciniphila concentrations with various metabolically-beneficial outcomes [30]. In this way $A$. muciniphila reveals to be a promising candidate in the understanding of the complex role of intestinal microbes in metabolic disorders even if data are still somewhat controversial.

In summary, evidence suggests that gut microbiota plays a critical role in the energy balance by fermentation of carbohydrates in SCFA. Gut microbiota composition appears to be involved in the pathogenesis of diabetes, but further interventional studies are needed to use it as a diagnostic and therapeutic tool.

\subsection{Lipid Metabolism}

\subsubsection{Animal Studies}

It is supposed that HFD may affect epithelial integrity, leading to impaired intestinal permeability and, consequently, to metabolic endotoxemia and systemic inflammation [32]. Chronic exposition to low-dose lipopolysaccharide (LPS) in mice led to hepatic fat deposition, insulin resistance (IR), hyperlipidemia, adipose tissue macrophages infiltration, and obesity, similar as after feeding a HFD [33,34]. Furthermore, these effects were abolished when TLR4 (Toll-like receptor, directly involved in LPS binding) knockout mice were fed a HFD, or $o b / o b$ mice and HFD-fed mice were treated with antibiotics or prebiotics [32].

Another complex diet-independent effect of microbiota on host metabolism is mediated by bacterial compounds, such as peptidoglycan and flagellin, that are able to activate inflammatory pathways [35]. For example, TLR5 is a pattern recognizer for flagellin, which can modulate intestinal homeostasis by activating various intracellular signaling pathways. TLR5-/- mice show a metabolic phenotype, exhibiting gut microbiome modifications, dyslipidemia, hypertension, IR, and obesity. Similarly to other studies, colonization of germ-free mice with TLR5-/- mice caecum microbes, led to a metabolic phenotype [36].

Studies in rodents genetically predisposed to obesity $(o b / o b)$, first revealed an increase in the Firmicutes/Bacteroidetes ratio [37] and analogous differences were observed in the gut microbiota in human obesity $[37,38]$. 
Interestingly, it has been clearly shown that the obese phenotype is a transmissible trait, by transplanting the caecal microbiome from obese mice into germ-free mice who developed the same phenotype of the donor $[39,40]$. Similarly, when germ-free mice were colonized with a caecum-derived microbiome of conventional mice, the amount of the total body fat increased and insulin sensitivity decreased [41].

A recent paper showed that colonization of germ-free mice with fecal microbiota from twin pairs discordant for obesity resulted in an obese phenotype in mice receiving microbiota from the obese twin, while mice receiving microbiota from the lean twin showed less weight gain and adiposity [42]. In the same study, authors also showed that cohousing of $o b / o b$ mice and lean mice led to the acquisition of the gut microbiota of the lean rodents by $o b / o b$ mice but not to the acquisition by lean mice of the $o b / o b$ mice microbiota. In addition, cohousing of $o b / o b$ mice and lean mice fed with high vegetables and fruit, a low-fat diet (LFD), resulted in a greater acquisition of microbes of the lean mice by $o b / o b$ rodents.

A recent study showed that the increased levels of acetate in dysbiosis stimulated the parasympathetic nervous system which, in turn, enhanced the secretion of glucose-stimulated insulin and ghrelin, leading to hyperphagia and obesity [43].

Overall, these findings suggest an active role of gut microbiome in the development of obesity, and the major mechanism involved appears to be the more efficient energy harvest from food [44].

\subsubsection{Human Studies}

Several studies demonstrated that obese patients usually show chronic adipose tissue inflammation and that the obese-associated gut microbiome was related with a high production of pro-inflammatory cytokines [45]. In addition, several, but not all, human adult evidence showed a decrease of the diversity of the microbiota and an increased Firmicutes/Bacteroidetes ratio [46]. Weight loss and a LFD reversed the obese core microbiome versus the healthy microbiota, by increasing the relative proportion of Bacteroidetes spp. and the bacterial diversity [47]. Furthermore, after bariatric surgery, levels of Bacteroidetes and Prevotella negatively correlated with adiposity and energy harvest [48].

Recent data on the gut fungal species of obese humans showed a reduced family biodiversity in obese individuals but no modifications in the richness of the gut mycobiome between obese and healthy subjects [49].

In summary, animal and human evidence described an 'obese core microbiome' which seems to be involved in the pathogenesis of obesity.

\subsection{Gut Microbiota and NAFLD}

The first evidence for a putative role of the gut microflora in NAFLD was suggested more than 20 years ago in patients with small intestinal bacterial overgrowth (SIBO) who were prone to develop NAFLD, and in a rat model with a blind intestinal loop in which hepatic injury was prevented by antibiotics [50].

An human study showed an increased gut permeability and prevalence of SIBO in NAFLD patients [51].

Recent studies focused on the increased endogenous ethanol production by the gut microbiota that is primary involved in NAFLD development [52,53]. Indeed, $o b / o b$ mice showed an increase in breath ethanol amount, while normal ethanol levels were observed if mice were treated with neomycin [54].

Convincing evidence also demonstrated that the microbiota-dependent choline conversion into methylamines in strain 12956 on a HFD decreases the bioavailability of choline mimicking the effects achieved by choline-deficient diets [55]. In this study, the authors observed that dietary choline depletion induced gut microbiota modification, and that Erysipelotrichi and Gammaproteobacteria levels were associated with changes in liver fat.

A recent study demonstrated that differences in intestinal microbiota composition could explain the varying response to a HFD in mice [56]. In this study, two donor C57BL/6J mice were identified 
on the basis of their responses to a high-fat diet (HFD); although both groups showed similar body weight gain, one mouse, called the 'responder', displayed hyperglycemia and systemic inflammation, whereas the other, called a 'non-responder', was normoglycemic. When the microbiota of both groups were transplanted into germ-free mice which were then fed with the same HFD, only mice colonized with 'responders' microbiota showed hyperglycemia and fatty liver disease, in absence of systemic and hepatic inflammation.

Moreover, an interventional study on ApoE- / - mice, a genetic model of dyslipidemia, intestinal inflammation, and steatohepatitis, showed that the administration of the probiotic VSL\#3 improved insulin resistance, and reduced the aortic plaque extension, mesenteric adipose tissue inflammation, and steatohepatitis [57].

A human study demonstrated that the administration of Bifidobacterium longum with fructo-oligosaccharides, plus lifestyle modifications, were able to significantly reduce serum aspartate transaminase (AST) levels, tumor necrosis factor (TNF)- $\alpha$, CRP (C-reactive protein), HOMA-IR (Homeostasis Assessment Model-Insulin Resistance), serum endotoxin, steatosis, and the non-alcoholic steatohepatitis (NASH) activity index when compared to lifestyle modification alone [58].

Dysbiosis-driven inflammatory response seems to play a major role in the pathogenesis of NAFLD. Intestinal microorganisms have highly conserved molecules, named "pathogen associated molecular patterns" (PAMPs) which are recognized specifically by pattern recognition receptors (PRRs), such as TLRs and nucleotide binding oligomerization domain-like receptors (NLRs). Several studies have shown that PRR stimulation can increase pro-inflammatory cytokines and chemokines by different intracellular signaling cascades, while commensal microbiota are able to counteract this inflammatory response by interfering in TLR-dependent nuclear factor kappa B (NF-kB) transcription [59-61]. The multimeric signaling platforms, called 'inflammasomes', appear to be primarily involved in the gut microbiota-driven liver steatosis and inflammation. The inflammasome, which is frequently identified by its first sensing molecules, such as NLRP6 and NLRP3 (NOD-like receptors, pyrin domain containing 6 and 3), have common pathways leading to interleukin (IL)-18 and IL-1 activation via caspase-1 activation. Inflammasome-deficient mice showed a reduction of Firmicutes and an increase of Bacteroidetes, associated with increased steatosis and inflammation via TLR4 and TLR9 activation, leading to enhanced hepatic TNF-transcription [62]. Co-housing of inflammasome-deficient mice with wild-type mice resulted in exacerbation of obesity and steatosis, concluding that NLRP6 and NLRP3 inflammasomes negatively regulate NAFLD/NASH progression. Furthermore, co-housing mice defective in TLR4 and TLR with inflammasome-deficient mice did not worsen NAFLD/NASH [63].

In summary, evidences suggest that dysbiosis may play a critical role in the development of NAFLD/NASH by metabolic and inflammatory pathways.

\subsection{Cardiovascular Disease}

Gut microbiota composition is modified not only in diabetes, obesity, and NAFLD, with adverse cardiovascular outcomes, but also in hypertension. Indeed, animals with hypertension showed decreased gut bacterial richness and diversity with associated reduced levels of acetate and butyrate which negatively correlate with systemic inflammation [64]. Furthermore, several studies showed that the "metabolic endotoxemia" caused by the exposure to LPS promoted a systemic low-grade inflammation with an increased cardiovascular risk [65,66]. Indeed, the binding of TLR4 by LPS, and the activation of an immune response, triggered the release of proinflammatory molecules that promoted endothelial dysfunction, oxidation of low-density lipoproteins (LDLs), thrombogenesis, and the formation and rupture of the atherosclerotic plaque [66].

Population studies supported a relation between infection and CVD, in consideration of higher cardiovascular risk and blood pressure in patients affected by periodontal disease $[67,68]$. Mounting evidence in animals and in humans is accumulating showing that gut microbiota is associated with CVD [69]. One study failed to show any overall difference in fecal microbiota composition of patients with atherosclerosis, however, gut and atherosclerotic plaque microbiota 
showed several operational taxonomic units (OTUs) [70]. Indeed, atherosclerotic plaque was shown to harbor its own microbiota dominated by Proteobacteria and Collinsella [71].

Furthermore, a meta-analysis of clinical trials of antibiotics therapy in people with atherosclerosis failed to demonstrate their positive effect on cardiovascular mortality [72]. Nowadays, only one prospective randomized trial with azithromycin performed for secondary prophylaxis of coronary disease failed to reduce cardiovascular event rates [73].

Metabolomic analyses of plasma samples in humans identified novel metabolites and connecting pathways related with cardiovascular risk [74]. Major differences were found in choline, betaine, and trimethylamine $\mathrm{N}$-oxide (TMAO), metabolites linked to phosphatidylcholine (PC) metabolism. Choline is known to be an essential nutrient [75] and its dietary deficiency can lead to muscle damage and liver steatosis. TMAO arises from the bacterial metabolism of choline via an intermediate trimethylamine (TMA), which reaches the liver and is converted into TMAO by oxidizing flavin monooxygenases 3 (FMO3) [76]. TMAO was undetectable in germ-free mice following a PC or carnitine challenge, but conventionalization of the rodents increased TMAO levels [77]. Similarly, when mice were treated with a cocktail of antibiotics, PC administration did not result in TMAO. Oral, but not parental, delivery of phosphatidylcholine was associated to higher levels of TMAO, suggesting that gut metabolic step is required for TMAO production. Interestingly, TMAO administration to apolipoprotein E-null mice was observed to produce macrophage foam cell formation in both the artery wall and the peritoneal cavity and to enhance aortic root atherosclerotic plaque development.

In a large cohort study of over 4000 patients undergoing elective coronary angiography, TMAO levels were able to predict major adverse cardiac events independently from traditional CV risk factors [78]. Blood choline and carnitine levels were also predictors of major cardiac events with respect to stable coronary artery disease, but only when TMAO levels were concomitantly increased [76].

In summary, animal and human evidence suggest that the gut microbiota plays a contributory role in the development of CVD but need further studies to use the gut microbiota as a new target for prevention and treatment of CVD.

\section{Concluding Remarks}

Over the last years, gut microbiota has emerged as a fascinating "new organ", involved in many intestinal and extra-intestinal pathologies. New sequencing techniques led to the discovery of a huge complexity of the microbiome and to the identification of potential genes involved in gut microbiota-host interaction.

Exciting new data suggest a clear contributory role for gut microbes in cardiometabolic disorders, such as diabetes, obesity, NAFLD/NASH, and atherosclerosis. However, more interest should be paid to the association with metabolomics, metagenomic, and functional studies, supplemented by prospective observational and interventional studies. The exploration of gut microbiota composition and function has now become a field of interest that offers a new frontier to discover the complex human host physiology and disease and providing new biomarkers and innovative therapeutic approaches.

Acknowledgments: Financial support: Grant PRIN 2010-2011 (Prot. N. 2010C4JJWB) (to A.Gr.), Catholic University Linea D1 (to A.Gr.) and Linea D3/2013 (to A.Ga. and A.Gr.).

Author Contributions: Marco Sanduzzi Zamparelli, Debora Compare, Pietro Coccoli, Alba Rocco, Olga Maria Nardone and Giuseppe Marrone revised and analized the literature and wrote the revied; Antonio Gasbarrini, Antonio Grieco, Gerardo Nardone and Luca Miele wrote the paper and revised the text.

Conflicts of Interest: The authors declare no conflict of interest.

\section{References}

1. Go, A.S.; Mozaffarian, D.; Roger, V.L.; Benjamin, E.J.; Berry, J.D.; Blaha, M.J.; Dai, S.; Ford, E.S.; Fox, C.S.; Franco, S.; et al. Heart disease and stroke statistics-2014 update: A report from the American Heart Association. Circulation 2014, 129, e28-e292. [CrossRef] [PubMed] 
2. O'Donnell, C.J.; Nabel, E.G. Genomics of cardiovascular disease. N. Engl. J. Med. 2011, 365, $2098-2109$. [PubMed]

3. Ripatti, S.; Tikkanen, E.; Orho-Melander, M.; Havulinna, A.S.; Silander, K.; Sharma, A.; Guiducci, C.; Perola, M.; Jula, A.; Sinisalo, J.; et al. A multilocus genetic risk score for coronary heart disease: Case-control and prospective cohort analyses. Lancet 2010, 376, 1393-1400. [CrossRef]

4. Ley, R.E.; Peterson, D.A.; Gordon, J.I. Ecological and evolutionary forces shaping microbial diversity in the human intestine. Cell 2006, 124, 837-848. [CrossRef] [PubMed]

5. Neish, A.S. Microbes in gastrointestinal health and disease. Gastroenterology 2009, 136, 65-80. [CrossRef] [PubMed]

6. Tremaroli, V.; Bäckhed, F. Functional interactions between the gut microbiota and host metabolism. Nature 2012, 489, 242-249. [CrossRef] [PubMed]

7. Yatsunenko, T.; Rey, F.E.; Manary, M.J.; Trehan, I.; Dominguez-Bello, M.G.; Contreras, M.; Magris, M.; Hidalgo, G.; Baldassano, R.N.; Anokhin, A.P.; et al. Human gut microbiome viewed across age and geography. Nature 2012, 486, 222-227. [PubMed]

8. Qin, J.; Li, R.; Raes, J.; Arumugam, M.; Burgdorf, K.S.; Manichanh, C.; Nielsen, T.; Pons, N.; Levenez, F.; Yamada, T.; et al. A human gut microbial gene catalogue established by metagenomic sequencing. Nature 2010, 464, 59-65. [CrossRef] [PubMed]

9. Cox, L.M.; Yamanishi, S.; Sohn, J.; Alekseyenko, A.V.; Leung, J.M.; Cho, I.; Kim, S.G.; Li, H.; Gao, Z.; Mahana, D.; et al. Altering the intestinal microbiota during a critical developmental window has lasting metabolic consequences. Cell 2014, 158, 705-721. [CrossRef] [PubMed]

10. Bailey, L.C.; Forrest, C.B.; Zhang, P.; Richards, T.M.; Livshits, A.; DeRusso, P.A. Association of antibiotics in infancy with early childhood obesity. JAMA Pediatr. 2014, 168, 1063-1069. [CrossRef] [PubMed]

11. De Filippo, C.; Cavalieri, D.; Di Paola, M.; Ramazzotti, M.; Poullet, J.B.; Massart, S.; Collini, S.; Pieraccini, G.; Lionetti, P. Impact of diet in shaping gut microbiota revealed by a comparative study in children from Europe and rural Africa. Proc. Natl. Acad. Sci. USA 2010, 107, 14691-14696. [CrossRef] [PubMed]

12. Matsumoto, M.; Inoue, R.; Tsukahara, T.; Ushida, K.; Chiji, H.; Matsubara, N.; Hara, H. Voluntary running exercise alters microbiota composition and increases n-butyrate concentration in the rat cecum. Biosci. Biotechnol. Biochem. 2008, 72, 572-576. [CrossRef] [PubMed]

13. Flint, H.J.; Bayer, E.A.; Rincon, M.T.; Lamed, R.; White, B.A. Polysaccharide utilization by gut bacteria: Potential for new insights from genomic analysis. Nat. Rev. Microbiol. 2008, 6, 121-131. [CrossRef] [PubMed]

14. Bäckhed, F.; Ding, H.; Wang, T.; Hooper, L.V.; Koh, G.Y.; Nagy, A.; Semenkovich, C.F.; Gordon, J.I. The gut microbiota as an environmental factor that regulates fat storage. Proc. Natl. Acad. Sci. USA 2004, 101, 15718-15723. [CrossRef] [PubMed]

15. Brown, A.J.; Goldsworthy, S.M.; Barnes, A.A.; Eilert, M.M.; Tcheang, L.; Daniels, D.; Muir, A.I.; Wigglesworth, M.J.; Kinghorn, I.; Fraser, N.J.; et al. The Orphan G protein-coupled receptors GPR41 and GPR43 are activated by propionate and other short chain carboxylic acids. J. Biol. Chem. 2003, 278, 11312-11319. [CrossRef] [PubMed]

16. Kimura, I.; Ozawa, K.; Inoue, D.; Imamura, T.; Kimura, K.; Maeda, T.; Terasawa, K.; Kashihara, D.; Hirano, K.; Tani, T.; et al. The gut microbiota suppresses insulin-mediated fat accumulation via the short-chain fatty acid receptor GPR43. Nat. Commun. 2013, 4, 1829. [CrossRef] [PubMed]

17. De Vadder, F.; Kovatcheva-Datchary, P.; Goncalves, D.; Vinera, J.; Zitoun, C.; Duchampt, A.; Bäckhed, F.; Mithieux, G. Microbiota-generated metabolites promote metabolic benefits via gut-brain neural circuits. Cell 2014, 156, 84-96. [CrossRef] [PubMed]

18. Tolhurst, G.; Heffron, H.; Lam, Y.S.; Parker, H.E.; Habib, A.M.; Diakogiannaki, E.; Cameron, J.; Grosse, J.; Reimann, F.; Gribble, F.M. Short-chain fatty acids stimulate glucagon-like peptide-1 secretion via the G-protein-coupled receptor FFAR2. Diabetes 2012, 61, 364-371. [CrossRef] [PubMed]

19. Samuel, B.S.; Shaito, A.; Motoike, T.; Rey, F.E.; Backhed, F.; Manchester, J.K.; Hammer, R.E.; Williams, S.C.; Crowley, J.; Yanagisawa, M.; et al. Effects of the gut microbiota on host adiposity are modulated by the short-chain fatty-acid binding G protein-coupled receptor, GPR41. Proc. Natl. Acad. Sci. USA 2008, 105, 16767-16772. [CrossRef] [PubMed]

20. Yadav, H.; Lee, J.H.; Lloyd, J.; Walter, P.; Rane, S.G. Beneficial metabolic effects of a probiotic via butyrate-induced GLP-1 hormone secretion. J. Biol. Chem. 2013, 288, 25088-25097. [CrossRef] [PubMed] 
21. Swann, J.R.; Want, E.J.; Geier, F.M.; Spagou, K.; Wilson, I.D.; Sidaway, J.E.; Nicholson, J.K.; Holmes, E. Systemic gut microbial modulation of bile acid metabolism in host tissue compartments. Proc. Natl. Acad. Sci. USA 2011, 108 (Suppl. 1), 4523-4530. [CrossRef] [PubMed]

22. Sinal, C.J.; Tohkin, M.; Miyata, M.; Ward, J.M.; Lambert, G.; Gonzalez, F.J. Targeted disruption of the nuclear receptor FXR/BAR impairs bile acid and lipid homeostasis. Cell 2000, 102, 731-744. [CrossRef]

23. Prawitt, J.; Abdelkarim, M.; Stroeve, J.H.; Popescu, I.; Duez, H.; Velagapudi, V.R.; Dumont, J.; Bouchaert, E.; van Dijk, T.H.; Lucas, A.; et al. Farnesoid $X$ receptor deficiency improves glucose homeostasis in mouse models of obesity. Diabetes 2011, 60, 1861-1871. [CrossRef] [PubMed]

24. Thomas, C.; Gioiello, A.; Noriega, L.; Strehle, A.; Oury, J.; Rizzo, G.; Macchiarulo, A.; Yamamoto, H.; Mataki, C.; Pruzanski, M.; et al. TGR5-mediated bile acid sensing controls glucose homeostasis. Cell Metab. 2009, 10, 167-177. [CrossRef] [PubMed]

25. Everard, A.; Lazarevic, V.; Derrien, M.; Girard, M.; Muccioli, G.G.; Neyrinck, A.M.; Possemiers, S.; van Holle, A.; François, P.; de Vos, W.M.; et al. Responses of gut microbiota and glucose and lipid metabolism to prebiotics in genetic obese and diet-induced leptin-resistant mice. Diabetes 2011, 60, 2775-2786. [CrossRef] [PubMed]

26. Hansen, C.H.; Krych, L.; Nielsen, D.S.; Vogensen, F.K.; Hansen, L.H.; Sørensen, S.J.; Buschard, K.; Hansen, A.K. Early life treatment with vancomycin propagates Akkermansia muciniphila and reduces diabetes incidence in the NOD mouse. Diabetologia 2012, 55, 2285-2294. [CrossRef] [PubMed]

27. Qin, J.; Li, Y.; Cai, Z.; Li, S.; Zhu, J.; Zhang, F.; Liang, S.; Zhang, W.; Guan, Y.; Shen, D.; et al. A metagenome wide association study of gut microbiota in type 2 diabetes. Nature 2012, 490, 55-60. [CrossRef] [PubMed]

28. Karlsson, F.H.; Tremaroli, V.; Nookaew, I.; Bergström, G.; Behre, C.J.; Fagerberg, B.; Nielsen, J.; Bäckhed, F. Gut metagenome in European women with normal, impaired and diabetic glucose control. Nature 2013, 498, 99-103. [CrossRef] [PubMed]

29. Larsen, N.; Vogensen, F.K.; van den Berg, F.W.; Nielsen, D.S.; Andreasen, A.S.; Pedersen, B.K.; Al-Soud, W.A.; Sørensen, S.J.; Hansen, L.H.; Jakobsen, M. Gut microbiota in human adults with type 2 diabetes differs from non-diabetic adults. PLoS ONE 2010, 5, e9085. [CrossRef] [PubMed]

30. Shin, N.R.; Lee, J.C.; Lee, H.Y.; Kim, M.S.; Whon, T.W.; Lee, M.S.; Bae, J.W. An increase in the Akkermansia spp. population induced by metformin treatment improves glucose homeostasis in diet-induced obese mice. Gut 2014, 63, 727-735. [CrossRef] [PubMed]

31. Everard, A.; Belzer, C.; Geurts, L.; Ouwerkerk, J.P.; Druart, C.; Bindels, L.B.; Guiot, Y.; Derrien, M.; Muccioli, G.G.; Delzenne, M.M.; et al. Cross-talk between Akkermansia muciniphila and intestinal epithelium controls diet-induced obesity. Proc. Natl. Acad. Sci. USA 2013, 110, 9066-9071. [CrossRef] [PubMed]

32. Cani, P.D.; Bibiloni, R.; Knauf, C.; Waget, A.; Neyrinck, A.M.; Delzenne, N.M.; Burcelin, R. Changes in gut microbiota control metabolic endotoxemia-induced inflammation in high-fat diet-induced obesity and diabetes in mice. Diabetes 2008, 57, 1470-1481. [CrossRef] [PubMed]

33. Cani, P.D.; Amar, J.; Iglesias, M.A.; Poggi, M.; Knauf, C.; Bastelica, D.; Neyrinck, A.M.; Fava, F.; Tuohy, K.M.; Chabo, C.; et al. Metabolic endotoxemia initiates obesity and insulin resistance. Diabetes 2007, 56, 1761-1772. [CrossRef] [PubMed]

34. Erridge, C.; Attina, T.; Spickett, C.M.; Webb, D.J. A high-fat meal induces low-grade endotoxemia: Evidence of a novel mechanism of postprandial inflammation. Am. J. Clin. Nutr. 2007, 86, 1286-1292. [PubMed]

35. Clarke, T.B.; Davis, K.M.; Lysenko, E.S.; Zhou, A.Y.; Yu, Y.; Weiser, J.N. Recognition of peptidoglycan from the microbiota by Nod1 enhances systemic innate immunity. Nat. Med. 2010, 16, 228-231. [CrossRef] [PubMed]

36. Vijay-Kumar, M.; Aitken, J.D.; Carvalho, F.A.; Cullender, T.C.; Mwangi, S.; Srinivasan, S.; Sitaraman, S.V.; Knight, R.; Ley, R.E.; Gewirtz, A.T. Metabolic syndrome and altered gut microbiota in mice lacking Toll-like receptor 5. Science 2010, 328, 228-231. [CrossRef] [PubMed]

37. Ley, R.E.; Bäckhed, F.; Turnbaugh, P.; Lozupone, C.A.; Knight, R.D.; Gordon, J.I. Obesity alters gut microbial ecology. Proc. Natl. Acad. Sci. USA 2005, 102, 11070-11075. [CrossRef] [PubMed]

38. Tilg, H.; Kaser, A. Gut microbiome, obesity, and metabolic dysfunction. J. Clin. Investig. 2011, 121, $2126-2132$. [CrossRef] [PubMed]

39. Bäckhed, F.; Manchester, J.K.; Semenkovich, C.F.; Gordon, J.I. Mechanisms underlying the resistance to diet-induced obesity in germ-free mice. Proc. Natl. Acad. Sci. USA 2007, 104, 979-984. [CrossRef] [PubMed]

40. Turnbaugh, P.J.; Ley, R.E.; Mahowald, M.A.; Magrini, V.; Mardis, E.R.; Gordon, J.I. An obesity-associated gut microbiome with increased capacity for energy harvest. Nature 2006, 444, 1027-1031. [CrossRef] [PubMed] 
41. Sonnenburg, J.L.; Bäckhed, F. Diet microbiota interactions as moderators of human metabolism. Nature 2016, 535, 56-64. [CrossRef] [PubMed]

42. Ridaura, V.K.; Faith, J.J.; Rey, F.E.; Cheng, J.; Duncan, A.E.; Kau, A.L.; Griffin, N.W.; Lombard, V.; Henrissat, B.; Bain, J.R.; et al. Gut microbiota from twins discordant for obesity modulate metabolism in mice. Science 2013, 341, 1241214. [CrossRef] [PubMed]

43. Perry, R.J.; Peng, L.; Barry, N.A.; Cline, G.W.; Zhang, D.; Cardone, R.L.; Petersen, K.F.; Kibbey, R.G.; Goodman, A.L.; Shulman, G.I. Acetate mediates a microbiome-brain- $\beta$-cell axis to promote metabolic syndrome. Nature 2016, 534, 213-217. [CrossRef] [PubMed]

44. Tremaroli, V.; Kovatcheva-Datchary, P.; Bäckhed, F. A role for the gut microbiota in energy harvesting? Gut 2010, 59, 1589-1590. [CrossRef] [PubMed]

45. Gesta, S.; Blüher, M.; Yamamoto, Y.; Norris, A.W.; Berndt, J.; Kralisch, S.; Boucher, J.; Lewis, C.; Kahn, C.R. Evidence for a role of developmental genes in the origin of obesity and body fat distribution. Proc. Natl. Acad. Sci. USA 2006, 103, 6676-6681. [CrossRef] [PubMed]

46. Turnbaugh, P.J.; Hamady, M.; Yatsunenko, T.; Cantarel, B.L.; Duncan, A.; Ley, R.E.; Sogin, M.L.; Jones, W.J.; Roe, B.A.; Affourtit, J.P.; et al. A core gut microbiome in obese and lean twins. Nature 2009, 457, 480-484. [CrossRef] [PubMed]

47. Ley, R.E.; Turnbaugh, P.J.; Klein, S.; Gordon, J.I. Microbial ecology: Human gut microbes associated with obesity. Nature 2006, 444, 1022-1023. [CrossRef] [PubMed]

48. Furet, J.P.; Kong, L.C.; Tap, J.; Poitou, C.; Basdevant, A.; Bouillot, J.L.; Mariat, D.; Corthier, G.; Doré, J.; Henegar, C.; et al. Differential adaptation of human gut microbiota to bariatric surgery-induced weight loss: Links with metabolic and low-grade inflammation markers. Diabetes 2010, 59, 3049-3057. [CrossRef] [PubMed]

49. Mar Rodríguez, M.; Pérez, D.; Javier Chaves, F.; Esteve, E.; Marin-Garcia, P.; Xifra, G.; Vendrell, J.; Jové, M.; Pamplona, R.; Ricart, W.; et al. Obesity changes the human gut mycobiome. Sci. Rep. 2015, 5, 14600. [CrossRef] [PubMed]

50. Lichtman, S.N.; Keku, J.; Schwab, J.H.; Sartor, R.B. Hepatic injury associated with small bowel bacterial overgrowth in rats is prevented by metronidazole and tetracycline. Gastroenterology 1991, 100, 513-519. [CrossRef]

51. Miele, L.; Valenza, V.; La Torre, G.; Montalto, M.; Cammarota, G.; Ricci, R.; Mascianà, R.; Forgione, A.; Gabrieli, M.L.; Perotti, G.; et al. Increased intestinal permeability and tight junction alterations in nonalcoholic fatty liver disease. Hepatology 2009, 49, 1877-1887. [CrossRef] [PubMed]

52. Moschen, A.R.; Kaser, S.; Tilg, H. Non-alcoholic steatohepatitis: A microbiota-driven disease. Trends. Endocrinol. Metab. 2013, 24, 537-545. [CrossRef] [PubMed]

53. Miele, L.; Marrone, G.; Lauritano, C.; Cefalo, C.; Gasbarrini, A.; Day, C.; Grieco, A. Gut-liver axis and microbiota in NAFLD: Insight pathophysiology for novel therapeutic target. Curr. Pharm. Des. 2013, 19, 5314-5324. [CrossRef] [PubMed]

54. Cope, K.; Risby, T.; Diehl, A.M. Increased gastrointestinal ethanol production in obese mice: Implications for fatty liver disease pathogenesis. Gastroenterology 2000, 119, 1340-1347. [CrossRef] [PubMed]

55. Spencer, M.D.; Hamp, T.J.; Reid, R.W.; Fischer, L.M.; Zeisel, S.H.; Fodor, A.A. Association between composition of the human gastrointestinal microbiome and development of fatty liver with choline deficiency. Gastroenterology 2011, 140, 976-986. [CrossRef] [PubMed]

56. Le Roy, T.; Llopis, M.; Lepage, P.; Bruneau, A.; Rabot, S.; Bevilacqua, C.; Martin, P.; Philippe, C.; Walker, F.; Bado, A.; et al. Intestinal microbiota determines development of non-alcoholic fatty liver disease in mice. Gut 2013, 62, 1787-1794. [CrossRef] [PubMed]

57. Mencarelli, A.; Cipriani, S.; Renga, B.; Bruno, A.; D'Amore, C.; Distrutti, E.; Fiorucci, S. VSL\#3 resets insulin signaling and protects against NASH and atherosclerosis in a model of genetic dyslipidemia and intestinal inflammation. PLOS ONE 2012, 7, e45425.

58. Malaguarnera, M.; Vacante, M.; Antic, T.; Giordano, M.; Chisari, G.; Acquaviva, R.; Mastrojeni, S.; Malaguarnera, G.; Mistretta, A.; Li Volti, G.; et al. Bifidobacterium longum with fructo-oligosaccharides in patients with non alcoholic steatohepatitis. Dig. Dis. Sci. 2012, 57, 545-553. [CrossRef] [PubMed]

59. Zhang, G.; Ghosh, S. Toll-like receptor-mediated NF- $\mathrm{kB}$ activation: A phylogenetically conserved paradigm in innate immunity. J. Clin. Investig. 2001, 107, 13-19. [CrossRef] [PubMed] 
60. Macpherson, A.J.; Harris, N.L. Interactions between commensal intestinal bacteria and the immune system. Nat. Rev. Immunol. 2004, 4, 478-485. [CrossRef] [PubMed]

61. Compare, D.; Coccoli, P.; Rocco, A.; Nardone, O.M.; de Maria, S.; Cartenì, M.; Nardone, G. Gut-Liver axis: The impact of gut microbiota on non alcoholic fatty liver disease. Nutr. Metab. Cardiovasc. Dis. 2012, 22, 471-476. [CrossRef] [PubMed]

62. Henao-Mejia, J.; Elinav, E.; Jin, C.; Hao, L.; Mehal, W.Z.; Strowig, T.; Thaiss, C.A.; Kau, A.L.; Eisenbarth, S.C.; Jurczak, M.J.; et al. Inflammasome-mediated dysbiosis regulates progression of NAFLD and obesity. Nature 2012, 482, 179-185. [CrossRef] [PubMed]

63. Elinav, E.; Thaiss, C.A.; Flavell, R.A. Analysis of microbiota alterations in inflammasome-deficient mice. Methods Mol. Biol. 2013, 1040, 185-194. [PubMed]

64. Yang, T.; Santisteban, M.M.; Rodriguez, V.; Li, E.; Ahmari, N.; Carvajal, J.M.; Zadeh, M.; Gong, M.; Qi, Y.; Zubcevic, J.; et al. Gut dysbiosis is linked to hypertension. Hypertension 2015, 65, 1331-1340. [CrossRef] [PubMed]

65. Arroyo-Espliguero, R.; Avanzas, P.; Jeffery, S.; Kaski, J.C. CD14 and toll-like receptor 4: A link between infection and acute coronary events? Heart 2004, 90, 983-988. [CrossRef] [PubMed]

66. Curtiss, L.K.; Tobias, P.S. Emerging role of Toll-like receptors in atherosclerosis. J. Lipid. Res. Suppl. 2009, 165, S340-S345. [CrossRef] [PubMed]

67. Mattila, K.J.; Nieminen, M.S.; Valtonen, V.V.; Rasi, V.P.; Kesäniemi, Y.A.; Syrjälä, S.L.; Jungell, P.S.; Isoluoma, M.; Hietaniemi, K.; Jokinen, M.J. Association between dental health and acute myocardial infarction. BMJ 1989, 298, 779-781. [CrossRef] [PubMed]

68. Holmes, E.; Loo, R.L.; Stamler, J.; Bictash, M.; Yap, I.K.; Chan, Q.; Ebbels, T.; de Iorio, M.; Brown, I.J.; Veselkov, K.A.; et al. Human metabolic phenotype diversity and its association with diet and blood pressure. Nature 2008, 453, 396-400. [CrossRef] [PubMed]

69. Miele, L.; Giorgio, V.; Alberelli, M.A.; de Candia, E.; Gasbarrini, A.; Grieco, A. Impact of Gut Microbiota on Obesity, Diabetes, and Cardiovascular Disease Risk. Curr. Cardiol. Rep. 2015, 17, 120. [CrossRef] [PubMed]

70. Koren, O.; Spor, A.; Felin, J.; Fåk, F.; Stombaugh, J.; Tremaroli, V.; Behre, C.J.; Knight, R.; Fagerberg, B.; Ley, R.E.; Bäckhed, F. Human oral, gut, and plaque microbiota in patients with atherosclerosis. Proc. Natl. Acad. Sci. USA 2011, 108 (Suppl. 1), 4592-4598. [CrossRef] [PubMed]

71. Karlsson, F.H.; Fåk, F.; Nookaew, I.; Tremaroli, V.; Fagerberg, B.; Petranovic, D.; Bäckhed, F.; Nielsen, J. Symptomatic atherosclerosis is associated with an altered gut metagenome. Nat. Commun. 2012, 3, 1245. [CrossRef] [PubMed]

72. Andraws, R.; Berger, J.S.; Brown, D.L. Effects of antibiotic therapy on outcomes of patients with coronary artery disease: A meta-analysis of randomized controlled trials. JAMA 2005, 293, 2641-2647. [CrossRef] [PubMed]

73. Grayston, J.T.; Kronmal, R.A.; Jackson, L.A.; Parisi, A.F.; Muhlestein, J.B.; Cohen, J.D.; Rogers, W.J.; Crouse, J.R.; Borrowdale, S.L.; et al. ACES Investigators. Azithromycin for the secondary prevention of coronary events. N. Engl. J. Med. 2005, 352, 1637-1645. [CrossRef] [PubMed]

74. Wang, Z.; Klipfell, E.; Bennett, B.J.; Koeth, R.; Levison, B.S.; Dugar, B.; Feldstein, A.E.; Britt, E.B.; Fu, X.; Chung, Y.M.; et al. Gut flora metabolism of phosphatidylcholine promotes cardiovascular disease. Nature 2011, 472, 57-63. [CrossRef] [PubMed]

75. Zeisel, S.H.; Mar, M.H.; Howe, J.C.; Holden, J.M. Concentrations of choline-containing compounds and betaine in common foods. J. Nutr. 2003, 133, 2918.

76. Lever, M.; Slow, S. The clinical significance of betaine, an osmolyte with a key role in methyl group metabolism. Clin. Biochem. 2010, 43, 732-744. [CrossRef] [PubMed]

77. Tang, W.H.; Wang, Z.; Levison, B.S.; Koeth, R.A.; Britt, E.B.; Fu, X.; Wu, Y.; Hazen, S.L. Intestinal microbial metabolism of phosphatidylcholine and cardiovascular risk. N. Engl. J. Med. 2013, 368, 1575-1584. [CrossRef] [PubMed]

78. Wang, Z.; Tang, W.H.; Buffa, J.A.; Fu, X.; Britt, E.B.; Koeth, R.A.; Levison, B.S.; Fan, Y.; Wu, Y.; Hazen, S.L. Prognostic value of choline and betaine depends on intestinal microbiota-generated metabolite trimethylamine-N-oxide. Eur. Heart J. 2014, 35, 904-910. [CrossRef] [PubMed]

(c) 2016 by the authors; licensee MDPI, Basel, Switzerland. This article is an open access article distributed under the terms and conditions of the Creative Commons Attribution (CC-BY) license (http://creativecommons.org/licenses/by/4.0/). 